\title{
Individual Experience of Positive and Negative Growth is Asymmetric: Global Evidence from Subjective Well-being Data
}

\section{Citation}

De Neve, Jan-Emmanuel, George W. Ward, Femke De Keulenaer, Bert Van Landeghem, Georgios Kavetsos, and Michael I. Norton. "Individual Experience of Positive and Negative Growth is Asymmetric: Global Evidence from Subjective Well-being Data." Harvard Business School Working Paper, No. 15-021, October 2014.

\section{Permanent link}

http://nrs.harvard.edu/urn-3:HUL.InstRepos:13479076

\section{Terms of Use}

This article was downloaded from Harvard University's DASH repository, and is made available under the terms and conditions applicable to Open Access Policy Articles, as set forth at http:// nrs.harvard.edu/urn-3:HUL.InstRepos:dash.current.terms-of-use\#OAP

\section{Share Your Story}

The Harvard community has made this article openly available.

Please share how this access benefits you. Submit a story.

\section{Accessibility}




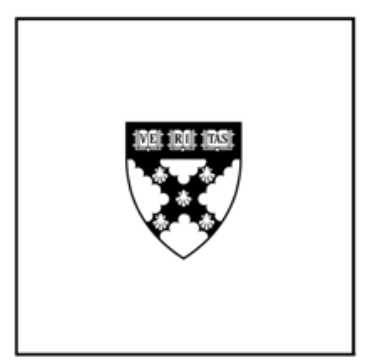

\section{Individual Experience of Positive and Negative Growth is Asymmetric: Global Evidence from Subjective Well-being Data}

Jan-Emmanuel De Neve George W. Ward Femke De Keulenaer Bert Van Landeghem Georgios Kavetsos Michael I. Norton

\section{Working Paper}

15-021

September 23, 2014

Copyright @ 2014 by Jan-Emmanuel De Neve, George W. Ward, Femke De Keulenaer, Bert Van Landeghem, Georgios Kavetsos, and Michael I. Norton

Working papers are in draft form. This working paper is distributed for purposes of comment and discussion only. It may not be reproduced without permission of the copyright holder. Copies of working papers are available from the author. 


\title{
Individual Experience of Positive and Negative Growth is Asymmetric: Global Evidence from Subjective Well-being Data*
}

\author{
Jan-Emmanuel De Neve ${ }^{\dagger} \quad$ George W. Ward ${ }^{\ddagger} \quad$ Femke De Keulenaer ${ }^{\S}$ \\ Bert Van Landeghem Georgios Kavetsos" Michael I. Norton**
}

September 23, 2014

\begin{abstract}
Are individuals more sensitive to losses than gains in macroeconomic growth? Using subjective well-being measures across three large data sets, we observe an asymmetry in the way positive and negative economic growth are experienced, with losses having more than twice as much impact on individual happiness as compared to equivalent gains. We use Gallup World Poll data drawn from 151 countries, BRFSS data taken from a representative sample of 2.5 million US respondents, and Eurobarometer data that cover multiple business cycles over four decades. This research provides a new perspective on the welfare cost of business cycles with implications for growth policy and our understanding of the long-run relationship between GDP and subjective well-being.
\end{abstract}

JEL Codes: D03, O11, D69, I39

Keywords: economic growth, business cycles, subjective well-being, loss aversion

\footnotetext{
${ }^{*}$ We thank Philippe Aghion, Dan Benjamin, Chris Boyce, Andrew Clark, Paul Dolan, Richard Easterlin, Carol Graham, Ori Heffetz, David Hemous, Richard Layard, George Loewenstein, Andrew Oswald, Amine Ouazad, Nick Powdthavee, Eugenio Proto, Matthew Rabin, Johannes Spinnewijn, Tim Van Zandt, and Fabrizio Zilibotti for comments and helpful suggestions. Participants at the 2014 AEA Annual Meeting, INSEAD Economics Symposium, and the LSE Centre for Economic Performance annual conference provided helpful comments. The usual disclaimer applies. De Neve and Ward gratefully acknowledge financial support from the US National Institute on Aging (Grant R01AG040640) and the Economic \& Social Research Council.

${ }^{\dagger}$ University College London and Centre for Economic Performance (LSE) j.deneve@ucl.ac.uk

${ }^{\ddagger}$ Centre for Economic Performance (LSE)

$\S$ Ipsos (previously at the Gallup Organization Europe)

IUniversity of Sheffield

"London School of Economics

${ }^{* *}$ Harvard Business School
} 


\section{Introduction}

This paper explores a simple question: are individuals more sensitive to losses than gains in macroeconomic growth? We use subjective well-being data drawn from three large and complementary data sets to investigate whether economic downturns are associated with decreases in individual well-being that are significantly different from increases in well-being from equivalent upswings. Our analyses reveal an asymmetry in the way that individuals experience positive and negative macroeconomic fluctuations. In fact, we find evidence that self-reported life satisfaction of individuals is between two and eight times more sensitive to negative growth as compared to positive economic growth.

Our findings speak to a number of topics in macroeconomics and behavioral economics. In particular, this work addresses the welfare cost of business cycles (Lucas, 1987, 2003) and recessions (Deaton, 2012). The use of an 'experienced utility' rather than a 'decision utility' measure (Kahneman et al., 1997) means that welfare is considered here in terms of subjective well-being rather than consumption. Although these welfare measures show considerable overlap (Benjamin et al., 2012) their relationship to the business cycle contrasts sharply. The difference between volatile versus smooth growth in terms of consumption is often considered small (Otrok, 2001; Lucas, 2003) but the psychological impact of volatile growth on individual well-being appears to be consistently large yet is mostly overlooked (with the notable exception of Wolfers (2003)). To our knowledge, there is no in-depth study that allows for heterogeneous impacts of positive and negative growth. Doing so may provide insight into the underlying mechanism that drives the welfare cost of volatile versus smooth business cycles in terms of human well-being.

The question whether people are more sensitive to losses than equivalent gains in economic growth relates to the famous behavioral finding on individual loss aversion that underpins prospect theory (Kahneman and Tversky, 1979). Rather than appealing to the concept of 'decision utility' and seeking to reveal loss averse preferences through individuals' choices and behavior, we employ self-reported life satisfaction as a proxy for 'experienced utility' to show that a greater welfare weight is placed on national income losses as compared to equivalent gains. Existing experimental evidence on prospect theory suggests that prospective losses loom larger than prospective gains in determining individuals' decisions and actions. We observe that individuals also experience losses more acutely than gains in a macroeconomic setting.

The central finding of this research also allows us to revisit the longstanding debate on the relationship between economic growth and well-being. Although we find that economic growth is significantly associated with well-being, when split across positive and negative economic growth we find that this result is mostly driven by the negative growth years. Recession years are significantly associated with losses in well-being. We do not, however, obtain an immediate relationship between positive growth years and well-being. This finding makes it imperative that future research also consider positive and negative economic growth 
Figure 1: Greece 1981-2012 (Eurobarometer)

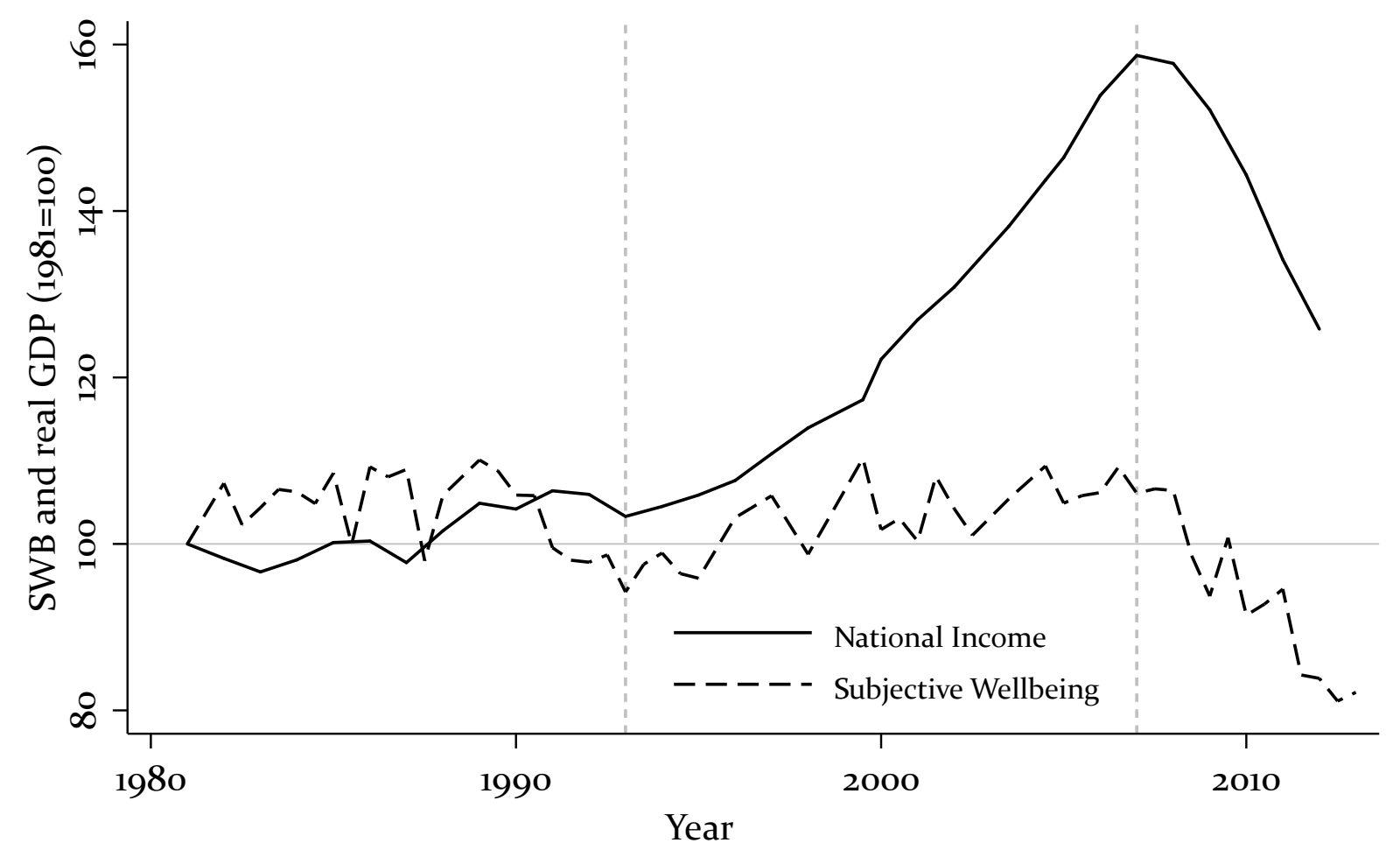

data separately in piecewise analyses when studying the relationship between economic growth and subjective well-being.

When considering the available longer-term data that cover entire business cycles, it would appear that well-being reports have not risen in most of the world's economically developed nations despite having almost doubled real GDP over the past four decades. This result echoes research by Easterlin et al. (2010). The "paradox" resulting from the conflicting findings in the short-term (using annual growth data that incorporates both positive and negative growth years) versus long-term (real GDP data that cover one or more business cycles) can perhaps be better understood in light of the results on macroeconomic "loss aversion" presented here. Recessions can rapidly undo the well-being gains from longer expansionary periods and lead to an insignificant relationship between national income and average well-being when considered in the long run. Figure 1 shows the available data for Greece in order to illustrate the asymmetric experience of positive and negative economic growth. The recession that started in 2008 led to a decrease in average well-being that erased all prior gains in well-being accumulated over more than a decade of consistent growth. Average well-being in Greece now stands at a level below historical records, despite real GDP remaining at a level well above recent historical figures.

To more formally explore this apparent macroeconomic loss aversion, we analyse data from three large data sets - the Eurobarometer, the Gallup World Poll, and the US Behavioural Risk Factor Surveillance System (BRFSS) — and employ piecewise (or 'segmented') regression models with country and state fixed effects that introduce separate terms for 
macroeconomic gains and losses. These data sets are complementary in that they each contribute a different setting to test for asymmetric sensitivity to gains and losses in economic growth. The Eurobarometer data include most European nations from about 1970 thus covering multiple business cycles and totaling over 1 million observations. The Gallup World Poll data is drawn from representative samples from 151 countries totaling over 1 million observations since 2005. The BRFSS data consists of 2.5 million observations drawn from representative samples of each US state since 2005.

The paper is structured as follows. Section II reviews the relevant existing literature and establishes the theoretical framework of the paper. Section III outlines the data and methods used to derive our results, which are presented in section IV. Section V includes follow-up analyses that explore possible mechanisms underlying macroeconomic loss aversion as well as a discussion of the scholarly and policy implications.

\section{Background}

\section{Subjective well-being as a measure of welfare}

In order to investigate how macroeconomic fluctuations are experienced by individuals, we use self-reported 'life satisfaction' as a welfare measure. Satisfaction with life is one of a number of ways that subjective well-being - often loosely referred to as 'happiness' - can be measured and is the most commonly used well-being measure employed in the economic literature - see for example Dolan et al. (2008) for a review. Besides 'life satisfaction' there are other measures of subjective well-being that focus more on positive and negative affect and also meaningfulness (Dolan and Metcalfe, 2012). Although different measures of subjective well-being can relate differently to economic variables such as income (Kahneman and Deaton, 2010; De Neve and Oswald, 2012) and personal circumstances such as unemployment (Knabe et al., 2010), our analyses will employ the more evaluative measure-i.e. life satisfaction - in line with most other relevant work in the field.

Measures of subjective well-being have been validated using a number of approaches. Oswald and $\mathrm{Wu}$ (2010) highlight the strong correlation between life satisfaction and objective measures of quality of life. People's self-reports are also systematically similar to evaluations of their happiness made by those around them (Sandvik et al., 1993). Further, studies have identified correlations between activity in the left prefrontal cortex of the brain - which is associated with satisfaction and pleasure - and higher reports of well-being (e.g. Sutton and Davidson, 1997; Urry et al., 2004; Rutledge et al., 2014). The reliability of subjective wellbeing measures has also been demonstrated by Krueger and Schkade (2008), who show the stability of self-reported life satisfaction over time (see also Schimmack and Oishi, 2005).

Economic research using subjective well-being data is burgeoning but such cardinal measures of 'experienced utility' remain distinct from the neoclassical notion of welfare that uses ordinal measures of 'decision utility' by way of revealed preferences (Kahneman et al., 1997; 
Rabin, 1998; Kahneman and Thaler, 2006) ${ }^{1}$. More recent work compares and bridges notions of experienced and decision utility. Evidence presented by Benjamin et al. (2012) suggests that measures of subjective well-being - and 'life satisfaction' in particular - are relatively good predictors of choice and can potentially be considered as a proxy (albeit an imperfect one $^{2}$ ) for the standard concept of decision utility (see also Benjamin et al., 2014; Perez-Truglia, 2010).

\section{Welfare cost of recessions}

While relevant research has mostly studied the general relationship between economic growth and happiness without considering positive and negative growth separately, some recent work has specifically explored losses in well-being from economic downturns. These studies center on the recent recession and find clear evidence for psychological costs of economic losses. Deaton (2012) uses individual daily self-reports of life satisfaction to show that subjective well-being tracked the US macroeconomy between 2008 and 2011, finding that life satisfaction declines when GDP falls and unemployment rises; although it is worth noting that the negative effect of the 2008 financial crisis on subjective well-being is hard to detect and had largely recovered by the end of 2010. ${ }^{3}$ Montagnoli and Moro (2014) use subjective well-being data drawn from a European sample to highlight the negative effects of banking crises on subjective well-being. Similarly, Kentikelenis et al. (2012) and Stuckler et al. (2011) show that economic downturns are associated with decreases in mental and physical health. In turn, Barr et al. (2012) and De Vogli et al. (2013) find evidence of an increased prevalence of suicide as a result of the recent great recession. These studies do not, however, study whether economic downturns have a disproportionate effect on subjective well-being as compared to economic upswings.

A larger literature exists on the welfare cost of business cycle volatility - when considering consumption patterns rather than well-being as the measure of human welfare. Studying how much extra consumption an individual would need to be indifferent between stable and volatile growth, Lucas (1987) shows that eliminating business cycle volatility would bring only minimal welfare gains, and he thus prioritizes the pursuit of long-run economic

\footnotetext{
${ }^{1}$ Note that we use the notion of 'experience' here to contrast between "experienced utility" (i.e. selfreported subjective well-being) and "decision utility" (i.e. revealed preferences) following Kahneman et al. (1997). Confusion may arise from the fact that self-reported measures of subjective well-being are subdivided into "evaluative" (i.e. life satisfaction) and "hedonic" measures. The latter set of subjective well-being measures assesses recent happiness 'experiences' (e.g. 'How happy were you yesterday') or employs the DayReconstruction-Method (Kahneman et al., 2004) - a duration-weighted measure of well-being experience for each activity the respondent engaged in over the span of a day.

${ }^{2}$ Benjamin et al. (2012) do find some systematic reversals for the link between decision utility and experience (see also Kahneman and Thaler, 2006).

${ }^{3}$ Aghion et al. (2014) also use daily self-reports drawn from Gallup (as well as data from the BRFSS) to show that creative destruction - principally measured as job turnover - has a positive effect on life satisfaction (through higher growth expectations) and a negative effect on subjective well-being (through higher risk of displacement). The overall effect of creative destruction on subjective well-being is unambiguously positive only when controlling for unemployment.
} 
growth over the stabilization of output (see also Otrok, 2001; Lucas, 2003). A growing number of scholars, however, question the notion that the welfare cost of business cycles would be negligible and provide evidence to the contrary (see e.g. Yellen and Akerlof, 2006; Barlevy, 2004; De Santis, 2007). Wolfers (2003) actually uses subjective well-being measures to estimate the welfare cost of business cycle volatility with regards to unemployment and inflation. He finds that greater unemployment volatility undermines well-being and that the same holds to a lesser extent for inflation. We contribute to this literature by suggesting that business cycle volatility depresses welfare because individual well-being is more sensitive to losses as compared to gains in economic growth.

\section{Loss aversion}

Our hypothesis that people are more sensitive to losses than equivalent gains in economic growth is related to research on individual loss aversion that underpins prospect theory. Originally a model of decision-making under risk developed by Kahneman and Tversky (1979) and later widened to encompass decisions under certainty (Tversky and Kahneman, 1991), prospect theory suggests that economic agents evaluate their prospects in terms of losses and gains relative to a reference point, and are loss averse in that the possibility of losses looms larger than that of gains. Individuals make decisions based on the anticipation that the experience of a loss will be more acute than that of a comparable gain, since 'the aggravation that one experiences in losing a sum of money appears to be greater than the pleasure associated with gaining the same amount' (Kahneman and Tversky, 1979, p. 279).

Loss aversion has been demonstrated in a variety of settings - see for example Barberis (2013) for an overview of the related literature. Other research has examined prospect theory in relation to the wider economy, typically seeking to reveal loss averse preferences through consumption behavior in response to macroeconomic fluctuations (Bowman et al., 1999; Rosenblatt-Wisch, 2008; Foellmi et al., 2011). However, as Kahneman (1999, p. 19) observes, 'the extent to which loss aversion is also found in experience is not yet known'. Although losses may loom larger than gains in revealed preferences that does not necessarily imply that losses are also experienced asymmetrically. Loss averse preferences can be the result of an 'affective forecasting error' explained by individuals overestimating the impact that losses will eventually have, as shown by Kermer et al. (2006) (see also Rick, 2011).

Rather than appealing to the concept of 'decision utility' and seeking to reveal loss averse preferences through individuals' choices and behavior, we employ self-reported well-being as a proxy for 'experienced utility' to show that a greater welfare weight is placed on national income losses than equivalent gains. We show that individuals experience losses more acutely than gains in a macroeconomic setting.

While our study focuses on macroeconomic fluctuations, related research has explored microeconomic effects on subjective well-being of gains and losses in personal income. Boyce et al. (2013) use subjective well-being data from a British and German panel to investigate 
the loss aversion hypothesis in relation to gains and losses in income. They find evidence for loss aversion in the experience of gains and losses in personal income and note that previous studies of the relationship between personal income and individual happiness may have overestimated the positive effect of income on well-being. Relatedly, Vendrik and Woltjer (2007) incorporate loss aversion into their analysis to consider whether the effect of income on subjective well-being is greater when it is below rather than above the level of a regional age-education reference group, while Senik (2009) tests the significance of other reference groups based on internal (e.g. respondent's past) and local (e.g. colleagues) comparisons.

\section{Economic growth and subjective well-being}

The central finding of this research also allows us to revisit the longstanding debate on the relationship between economic growth and well-being. The linkages between income, economic growth, and subjective well-being are the subject of much research. Within countries, wealthier individuals report higher life satisfaction than people who are less well off, a relationship that holds at any one point in time as well as over time, although the marginal income effect on happiness becomes weaker at higher levels of individual income (e.g. Blanchflower and Oswald, 2004; Ferrer-i Carbonell and Frijters, 2004; Layard et al., 2008; Kahneman and Deaton, 2010). ${ }^{4}$ At the country level, nations with higher GDP per capita have higher aggregate subjective well-being in cross-sectional analyses (Stevenson and Wolfers, 2008; Deaton, 2008; Helliwell et al., 2013) with some research finding evidence for a satiation point (Proto and Rustichini, 2013) while other research does not (Sacks et al., 2012).

The aggregate time-series relationship remains the subject of an important debate in the literature and centers around the question originally put forth by Easterlin (1974): Does economic growth improve the human lot? Most observers find that economic growth is positively associated with well-being but that over longer periods of time the relationship appears to be insignificant (e.g. Layard, 2005; Clark et al., 2008). The happiness-income paradox thus boils down to contrasting findings in the short versus long-term relationship between economic growth and happiness (Easterlin et al., 2010). For example, Di Tella et al. (2003) use the Eurobarometer and the General Social Survey to establish evidence of short-run co-movement of subjective well-being and macroeconomic variables. However, investigating longer-term first differences, Easterlin et al. (2010) fail to find the significant relationship between national income growth and aggregate well-being over the long run that one would expect given the cross-sectional as well as short-run time series relationships. Conversely, Sacks et al. (2013) employ fixed effects models to find a significant positive relationship between the level of (log) GDP and life satisfaction over time (see also Sacks et al., 2010, 2012) $)^{5}$.

\footnotetext{
${ }^{4}$ Recent studies raise the possibility of 'reverse causality' in the relationship between individual income and happiness by showing that subjective well-being can also be a driver of productivity and later earnings (De Neve and Oswald, 2012; Oswald et al., 2009).

${ }^{5}$ Sacks et al. (2013) reconcile the opposed findings on the long-term relationship between growth in well-
} 
We find that economic growth is associated with well-being but that this result is mostly driven by the negative growth years. Assessed over one or more business cycles, the disproportional sensitivity to recessions can undo the well-being gains from longer periods of positive growth and thus lead to a null relationship in the long run. Seen as such, the apparent paradox in the short versus long-term relationship between economic growth and happiness can thus be understood as the result of macroeconomic loss aversion.

\section{Data and Methods}

We use subjective well-being data from three complementary data sets: The Eurobarometer, covering a relatively small set of countries but over a longer period of four decades; the Gallup World Poll, offering a wider set of countries over a shorter period of time; and the Behavioural Risk Factor Surveillance System (BRFSS) providing quarterly data for each of the US states from 2005, allowing us to test our hypothesis within a single country. Annual economic growth data are obtained from the World Bank for the analyses conducted on the Gallup and Eurobarometer data and US quarterly state income data are obtained from the Bureau of Economic Analysis for the BRFSS analyses.

\section{Eurobarometer}

The Eurobarometer is an opinion survey carried out on behalf of the European Commission that has typically, though not always, taken place twice a year. For each wave, a random sample of approximately 1,000 individuals from each country in the European Union is interviewed on a range of issues including how satisfied they are with the life they lead. The response options are: very satisfied, fairly satisfied, not very satisfied, and not at all satisfied. This four category subjective well-being question has been included at least once every year from 1973 to 2012, apart from 1974.

The Eurobarometer began with 9 countries and has grown over time along with the expansion of the EU and the inclusion of additional member states. In fact, a number of countries joined the EU-and the Eurobarometer-after 2004 but are not included in our sample as there is only a comparatively small amount of data available for these (mostly Eastern European) nations that could bias our results; see Sacks et al. (2013) for a detailed discussion on the potential drawbacks of including these new EU member states in our analyses. (Eurobarometer countries excluded this way are, however, included in the Gallup World Poll data which span shorter time series.) The data we use come from an unbalanced panel of the so-called EU-15, for which the minimum time-series is 18 years and the maximum 39 years.

being and growth in GDP by pointing to the inclusion of controls for survey-specific fixed effects and the use by Easterlin et al. (2010) of country-years with non-representative sampling frames. 
Table 1: Descriptive Statistics: Eurobarometer

\begin{tabular}{rrrrrr}
\hline \hline Variable & Obs & Mean & Std Dev & Min & Max \\
\hline Reported life satisfaction & $1,049,972$ & 3.07 & 0.75 & 1 & 4 \\
GDP growth & 493 & 1.87 & 2.65 & -8.97 & 10.22 \\
Negative growth & 89 & -2.13 & 1.97 & -8.97 & -0.02 \\
Positive growth & 404 & 2.76 & 1.84 & 0.17 & 10.22 \\
GDP growth (t-1) & 493 & 1.93 & 2.57 & -8.97 & 10.22 \\
GDP per capita (2005 US \$) & 493 & 26,987 & 9621 & 12,228 & 74,021 \\
Unemployment rate & 493 & 7.99 & 4.08 & 0.03 & 25.13 \\
Inflation rate & 493 & 4.61 & 4.62 & -4.48 & 24.46 \\
\hline \hline
\end{tabular}

\section{Gallup World Poll}

The Gallup World Poll is a large-scale repeated cross-sectional survey initiated in 2005 covering more than 150 countries; although not all countries participated in all waves. The frequency of the survey is annual in most countries and quarterly in a small number of countries (e.g. Germany and the US). The data for the analyses reported in this article are drawn from the seven waves of the Gallup World Poll run between 2005/06 and 2012.

All samples in the Gallup World Poll are probability based and nationally representative of the resident population aged 15 and older. The typical Gallup World Poll survey interviews 1,000 individuals. In some large countries, such as China and Russia, sample sizes of at least 2,000 individuals are collected. Telephone surveys are used in countries where telephone coverage represents at least $80 \%$ of the population (or is the customary survey methodology). In Central and Eastern Europe, as well as in the developing world, including much of Latin America, the former Soviet Union countries, nearly all of Asia, the Middle East, and Africa, an area frame design is used for face-to-face interviewing. ${ }^{6}$

Gallup uses a standard set of core questions that has been translated into the major languages of the respective countries. The survey is based on a common questionnaire that asks respondents a broad set of questions on socio-economic background, civic engagement, and satisfaction with living standards. The survey also asks a variety of subjective wellbeing questions, including the Cantril Self-Anchoring Striving Scale (Cantril, 1965) where respondents are asked to select the "step" on a ladder scale that best represents their life; the steps on this ladder are numbered from 0 to 10 , where 0 indicates the worst possible life and 10 the best possible life.

\section{BRFSS}

The Behavioral Risk Factor Surveillance System (BRFSS) contains quarterly data obtained through telephone surveys and is carried out by the Centre for Disease Control and Prevention (CDC) in the United States. The primary aim is to collect data on the most important

\footnotetext{
${ }^{6}$ Details about the methodology for each country are available at http://www.gallup.com/se/128171/Country-Data-Set-Details-May-2010.aspx
} 
Table 2: Descriptive Statistics: Gallup World Poll

\begin{tabular}{rrrrrr}
\hline \hline Variable & Obs & Mean & Std Dev & Min & Max \\
\hline Reported life satisfaction & $1,008,073$ & 5.52 & 2.2 & 0 & 10 \\
GDP growth & 815 & 2.68 & 4.34 & -17.55 & 33.03 \\
Negative growth & 170 & -2.92 & 3.2 & -17.55 & 0 \\
Positive growth & 645 & 4.09 & 3.34 & 0.02 & 33.03 \\
GDP growth (t-1) & 815 & 3.02 & 4.56 & -14.42 & 33.03 \\
GDP per capita (2005 US \$) & 815 & 13,563 & 13,810 & 322 & 72,650 \\
Unemployment rate & 485 & 8.15 & 5.17 & 0.1 & 34.9 \\
Inflation rate & 786 & 5.96 & 5.62 & -13.23 & 59.22 \\
\hline \hline
\end{tabular}

risk factors leading to premature death, such as cigarette smoking, alcohol use, and hypertension. A four category life satisfaction question - with response categories: very satisfied, satisfied, dissatisfied, very dissatisfied - was included from 2005 until 2010. In most quarters, there have been surveys in 50 or 51 states, with outliers in 2008/1 (46 states) and 2009/1 (38 States). In total there are 1,197 state-quarter observations from 2005/1 to 2010/4.

The scale of the life satisfaction survey measure is rather limited with approximately $94 \%$ of respondents answering 'satisfied' or 'very satisfied'. The BRFSS samples a large number of US individuals with approximately 400,000 respondents per year, divided across the different states and different months of the year. The subjective well-being data are matched with quarterly state-personal income data from the Bureau of Economic Analysis and quarterly state level unemployment data and quarterly nationwide inflation data from the Bureau of Labour Statistics.

Table 3: Descriptive Statistics: BRFSS

\begin{tabular}{rrrrrr}
\hline \hline Variable & Obs & Mean & Std Dev & Min & Max \\
\hline Reported life satisfaction & $2,287,030$ & 3.387 & 0.628 & 1 & 4 \\
GDP growth & 1,222 & 0.13 & 0.846 & -3.963 & 3.261 \\
Negative growth & 446 & -0.746 & 0.627 & -3.963 & -0.001 \\
Positive growth & 776 & 0.632 & 0.457 & 0.005 & 3.261 \\
GDP growth $(\mathrm{t}-1)$ & 1,222 & 0.18 & 0.835 & -3.963 & 3.261 \\
State income per capita $(2005 \$)$ & 1,222 & 35,644 & 6,149 & 26,312 & 64,598 \\
Unemployment rate & 1,222 & 6.031 & 2.39 & 2.067 & 14.367 \\
Inflation rate & 1,222 & 0.580 & 0.983 & -2.828 & 2,195 \\
\hline \hline
\end{tabular}

\section{Empirical Strategy}

To investigate the relationship between economic growth and subjective well-being we estimate the equation

$$
Y_{i j t}=\beta_{1} X_{j t}+\xi_{j}+\gamma_{t}+\varepsilon_{i j t}
$$


where $Y_{i j t}$ is the (standardised) subjective well-being of individual $i$ in country $j$ in year $t$, and $X_{j t}$ is the rate of economic growth from year t- 1 to year t. In the case of the BRFSS $Y_{i j t}$ is the (standardised) subjective well-being of individual $i$ in U.S. state $j$ in quarter $t$, and $X_{j t}$ is the mean rate of economic growth over the previous four quarters. $\xi_{j}$ is an entity fixed effect, $\gamma_{t}$ a year fixed effect, and $\varepsilon_{i j t}$ an error term clustered on country-years (state-quarters). Heteroskedasticity and autocorrelation consistent (HAC), standard errors clustered on country-years (state-quarters), are reported throughout.

In the Eurobarometer and Gallup World Poll (i.e. the national level) models, country and year fixed effects are included. In the BRFSS models, state and season fixed effects are employed. Country(state)-specific intercepts diminish the threat of omitted variable bias by controlling for unobserved heterogeneity across countries (states), such that timeinvariant factors like culture and climate are controlled for. Time-specific intercepts control for time-variant trends and shocks that apply equally across the sample. Another important reason to include such intercepts is to partial out variance in survey design over time. Deaton (2012) shows that question ordering and context effects are typically substantial in relation to subjective well-being questions, particularly when political questions are asked prior to them (see also Sacks et al., 2013; Schwarz and Strack, 1999; Strack et al., 1988). In the Eurobarometer, for example, the question order has not remained constant over time. Further, each round has typically featured a section on a topical (usually social or political) theme, which has ranged widely in nature from survey to survey, and is likely to exert context effects on the life satisfaction response.

To test for any asymmetric effects of economic growth, we then fit a piecewise linear regression model that introduces separate terms for negative and positive growth, such that

$$
Y_{i j t}=\beta_{1} X_{j t}^{+}+\beta_{2}\left|X^{-}\right|_{j t}+\xi_{j}+\gamma_{t}+\varepsilon_{i j t}
$$

where $X^{+}$is equal to economic growth in country-years (state-quarters) in which growth is positive, 0 otherwise; and $X^{-}$is equal to the absolute value of the economic growth rate where growth is negative, 0 otherwise.

After establishing whether an asymmetry exists in the subjective experience of negative and positive economic growth, we gradually introduce a number of individual-level controls (age, age-squared, employment status, gender, education, and marriage status), lags, and macroeconomic controls (the natural logarithm of GDP per capita, the unemployment rate, and the inflation rate).

\section{Results}

Our main result is that, across all three data sets, subjective well-being is more sensitive to decreases in national income than it is to equivalent increases. Table 4 shows that subjective well-being is positively and significantly associated with the economic growth rate. A one 
unit increase in the growth rate is associated with a 0.017 standard deviation rise in wellbeing in the Eurobarometer sample, and a 0.005 standard deviation increase in the other two data sets.

Introducing separate terms for positive and negative growth-and thus allowing the slope gradient to differ for economic gains and losses - we find in all three data sets that the statistical relationship between economic growth and happiness appears to be driven principally by episodes of negative growth. The negative growth terms are greater in both magnitude and statistical significance. In the European sample, the coefficient for negative growth is around six times greater than that of positive growth, which is not well-defined statistically. For a 10\% economic contraction there would be a corresponding 0.41 standard deviation drop in life satisfaction, but an equivalent $10 \%$ expansion of the economy brings along a statistically ill-defined increase of only 0.07 standard deviation. These estimates correspond to a 0.55 decrease and a 0.09 increase on the 4-point life satisfaction scale, respectively.

Table 4: Economic Growth and Subjective Well-Being

\begin{tabular}{|c|c|c|c|c|c|c|}
\hline \multirow{3}{*}{ Economic Growth } & \multicolumn{2}{|c|}{ Eurobarometer } & \multicolumn{2}{|c|}{ Gallup World Poll } & \multicolumn{2}{|c|}{$\overline{\mathrm{BRFSS}}$} \\
\hline & (1) & $(2)$ & $(3)$ & (4) & $(5)$ & (6) \\
\hline & $\begin{array}{c}0.017^{* * *} \\
(0.005)\end{array}$ & & $\begin{array}{c}0.005^{* * *} \\
(0.002)\end{array}$ & & $\begin{array}{c}0.005^{* * *} \\
(0.001)\end{array}$ & \\
\hline Negative Growth & & $\begin{array}{c}-0.041^{* *} \\
(0.017)\end{array}$ & & $\begin{array}{c}-0.008^{* * *} \\
0.003\end{array}$ & & $\begin{array}{c}-0.008^{* * *} \\
(0.002)\end{array}$ \\
\hline Positive Growth & & $\begin{array}{c}0.007 \\
(0.004)\end{array}$ & & $\begin{array}{l}0.004^{*} \\
(0.002)\end{array}$ & & $\begin{array}{c}0.001 \\
(0.003)\end{array}$ \\
\hline Loss aversion ratio & & 6 & & 2 & & 8 \\
\hline$N_{\text {macro }}$ & 493 & 493 & 815 & 815 & 1222 & 1222 \\
\hline$N_{\text {micro }}$ & $1,049,972$ & $1,049,972$ & $1,008,073$ & $1,008,073$ & $2,283,596$ & $2,283,596$ \\
\hline$R^{2}$ & 0.005 & 0.006 & 0.001 & 0.001 & 0.001 & 0.001 \\
\hline
\end{tabular}

Clustered standard errors in parentheses

${ }^{*} p<0.1,{ }^{* *} p<0.05,{ }^{* * *} p<0.01$

Dependent variable: life satisfaction (standardised)

Country and year dummies included in models 1-4, state and season dummies in 5-6

Economic growth variables are the absolute value of negative or positive growth, 0 otherwise

Similarly, in the Gallup World Poll sample, which includes a wider range of countries over a shorter time span, a $10 \%$ economic contraction of the economy would be associated with a 0.08 standard deviation decrease in subjective well-being, yet an equivalent expansion is related with a rise in life satisfaction of only half the size, 0.04 standard deviation. With the BRFSS, a 10\% decrease in the mean growth rate over the previous four quarters is related with a concurrent 0.08 standard deviation decrease in life satisfaction in the current quarter, but a comparable increase in the growth rate is not significantly related with subjective well- 
being. From a human well-being perspective, the results from the three data sets would suggest that some 2 to 8 percent of economic growth would be required to offset just 1 percent of economic contraction.

The asymmetry in the relationship between economic growth and well-being can be seen clearly in Figure 2, which plots the coefficients for negative and positive growth separately on the $\mathrm{x}$-axis, and subjective well-being on the y-axis. This representation looks similar to the well-known utility function of prospect theory - showing that losses loom larger than gains in decision utility (Kahneman and Tversky, 1979). Here, Figure 2 suggests that individuals experience macroeconomic losses more acutely than equivalent gains in annual growth.

\section{Robustness}

In order to highlight the core asymmetry in the relationship between macroeconomic expansions and contractions with subjective well-being, Table 4 includes neither individual nor macroeconomic controls, except country (state) and year (season) fixed effects. Including a vector of personal controls hardly alters the growth coefficients, but does increase the $R^{2}$ values, since personal circumstances and characteristics inevitably explain a good deal of variance in life satisfaction.

It is plausible that the estimated negative impact of losses in growth on subjective well-being arises due to increases in unemployment that tend to accompany such economic contractions. Table 5 shows that the inclusion of a control for the aggregate level of unemployment does little to alter the loss aversion finding in the European case, and indeed seems to strengthen it in the American sample. Reflecting the well-established direct and indirect impact of joblessness, an increase in the unemployment rate is negatively associated with life satisfaction in Europe, a relationship that also holds when controlling for individual unemployment. Macroeconomic loss aversion in relation to economic growth is robust to inclusion of the unemployment rate in the Eurobarometer and BRFSS data but not in the Gallup data, offering somewhat mixed evidence on whether our finding on economic growth could reflect loss aversion to rising unemployment.

In the Gallup World Poll the inclusion of the unemployment rate leads to the loss of significance of the negative growth term and strengthens the positive growth term. Inclusion of the unemployment rate also leads to a decrease in the negative growth term for the European data, although the term remains significant. Such a decrease in the growth terms would be expected since growth and unemployment rates usually move in parallel. In the Gallup World Poll, the correlation between growth, and negative growth in particular, and the unemployment rate is stronger than in the European and American samples; an explanation for this difference in correlations can be found in the more diverse sample of countries in the Gallup World Poll. A strong correlation between these two predictors in our regression model means that the estimates for the effect of GDP growth on well-being, controlling for unemployment rate, tend to be less precise than if growth in GDP and un- 
Figure 2: Asymmetric Experience of Positive and Negative Growth

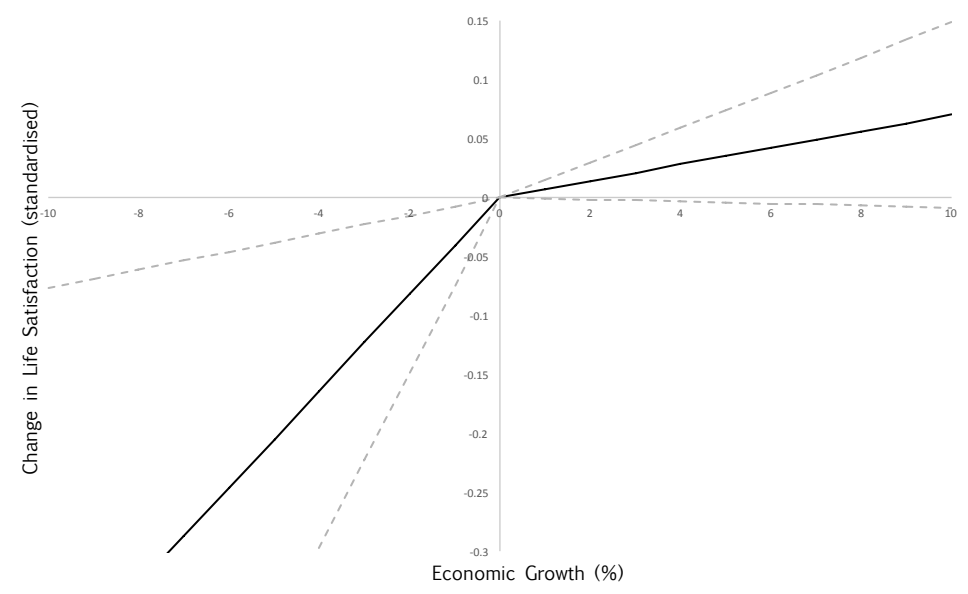

(a) Eurobarometer

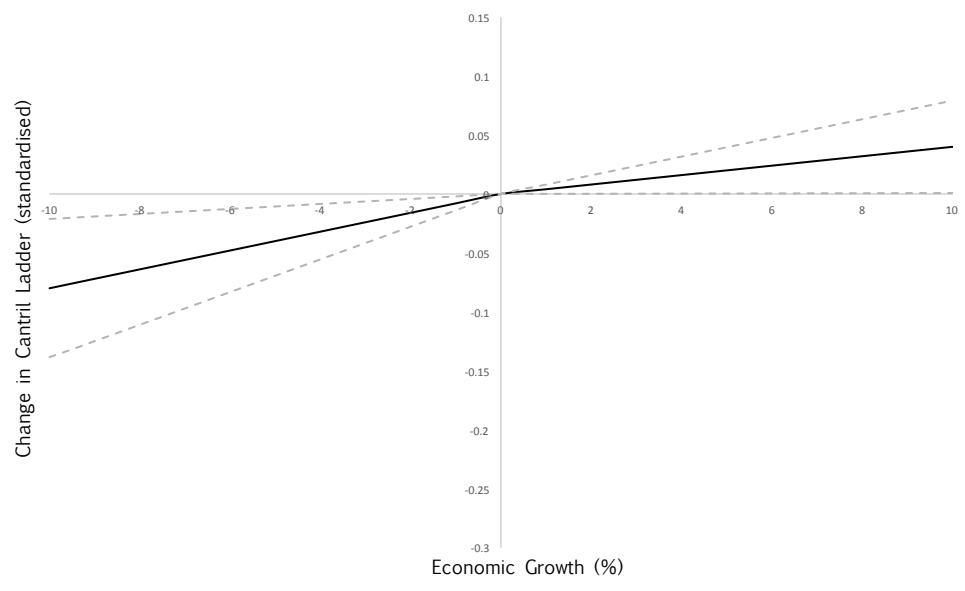

(b) Gallup World Poll

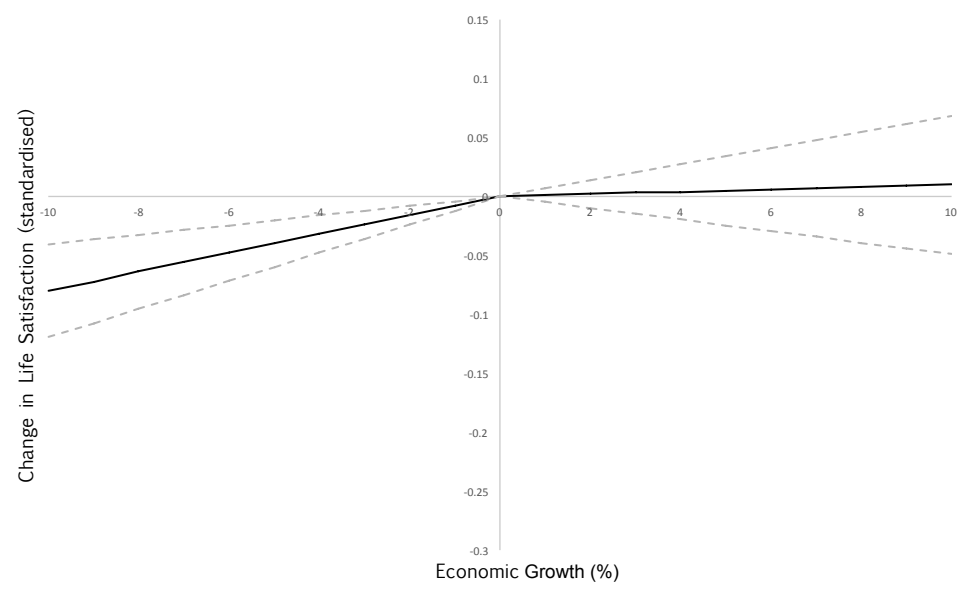

(c) BRFSS

Notes: Plots the coefficients for negative and positive growth taken from the regression analyses reported in Table 4. 95\% confidence intervals reported. 
Table 5: Asymmetric experience of positive and negative growth: The role of unemployment

\begin{tabular}{|c|c|c|c|c|c|c|}
\hline & \multicolumn{2}{|c|}{ Eurobarometer } & \multicolumn{2}{|c|}{ Gallup World Poll } & \multicolumn{2}{|c|}{ BRFSS } \\
\hline & $(1)$ & $(2)$ & (3) & (4) & $(5)$ & $(6)$ \\
\hline Economic Growth & $\begin{array}{c}0.011^{* * *} \\
(0.004)\end{array}$ & & $\begin{array}{c}0.004^{* *} \\
(0.002)\end{array}$ & & $\begin{array}{c}0.007 * * * \\
(0.002)\end{array}$ & \\
\hline Negative Growth & & $\begin{array}{c}-0.028^{* *} \\
(0.012)\end{array}$ & & $\begin{array}{l}-0.003 \\
(0.003)\end{array}$ & & $\begin{array}{c}-0.012^{* * * *} \\
(0.002)\end{array}$ \\
\hline Positive Growth & & $\begin{array}{c}0.004 \\
(0.004)\end{array}$ & & $\begin{array}{c}0.004^{* *} \\
(0.002)\end{array}$ & & $\begin{array}{c}0.001 \\
(0.002)\end{array}$ \\
\hline Unemployment Rate & $\begin{array}{c}-0.023^{* * *} \\
(0.002)\end{array}$ & $\begin{array}{c}-0.022^{* * *} \\
(0.003)\end{array}$ & $\begin{array}{c}-0.020^{* * *} \\
(0.003)\end{array}$ & $\begin{array}{c}-0.020^{* * *} \\
(0.003)\end{array}$ & $\begin{array}{l}0.001^{*} \\
(0.001)\end{array}$ & $\begin{array}{c}0.002^{* * *} \\
(0.001)\end{array}$ \\
\hline Loss Aversion Ratio & & 7 & & 1 & & 12 \\
\hline$N_{\text {macro }}$ & 493 & 493 & 485 & 485 & 1222 & 1222 \\
\hline$N_{\text {micro }}$ & $1,049,972$ & $1,049,972$ & 583,670 & 583,670 & $2,283,596$ & $2,283,596$ \\
\hline$R^{2}$ & 0.007 & 0.008 & 0.003 & 0.003 & 0.001 & 0.001 \\
\hline
\end{tabular}

Clustered standard errors in parentheses

${ }^{*} p<0.1,{ }^{* *} p<0.05,{ }^{* * *} p<0.01$

Dependent variable: life satisfaction (standardised)

Country and year dummies included in models 1-4, state and season dummies in 5-6

Economic growth variables are the absolute value of negative or positive growth, 0 otherwise

employment were uncorrelated. Given that the correlation between economic growth and unemployment was the greatest when focusing solely on countries with negative growth rates, the inclusion of the unemployment rate leads to the loss of significance of the negative growth term, but not of the positive growth term. We also note that, for many countries included in the Gallup World Poll, no information can be found on unemployment rates, and this is especially the case for recent years. As such, when adding the unemployment rate as control variable, the number of higher level observations in our model drops from 815 to 485, with an accompanying loss of statistical power.

In Table 6 we introduce a full set of individual and macroeconomic controls as well as one year lags of the economic growth variables. In the Eurobarometer sample, a control for the current level of GDP is not significant, which suggests that, at least in Europe, welfare is a function of changes rather than levels of national income.

In the Gallup World Poll, the level-of-GDP variable dominates. Several factors may help to explain this finding. First, compared to the European and American samples, the group of countries covered in the Gallup World Poll is characterized by a much larger variation in the current level of GDP. This larger variation may explain why the level-of-GDP variable is dominant in the Gallup data, while it does not enter significantly in the European sample. Secondly, the loss of significance of the growth terms in the Gallup data is linked to the fact that cross-sectional and longitudinal relationships are not fully distinguished in this model. 
Table 6: Asymmetric experience of positive and negative growth: The role of covariates

\begin{tabular}{|c|c|c|c|c|c|c|}
\hline \multirow{3}{*}{ Economic growth } & \multicolumn{2}{|c|}{ Eurobarometer } & \multicolumn{2}{|c|}{ Gallup World Poll } & \multicolumn{2}{|c|}{ BRFSS } \\
\hline & (1) & $(2)$ & $(3)$ & $(4)$ & $(5)$ & $(6)$ \\
\hline & $\begin{array}{c}0.008^{* *} \\
(0.004)\end{array}$ & & $\begin{array}{c}0.003 \\
(0.002)\end{array}$ & & $\begin{array}{c}0.004^{* * *} \\
(0.001)\end{array}$ & \\
\hline Negative growth & & $\begin{array}{c}-0.027^{* *} \\
(0.012)\end{array}$ & & $\begin{array}{c}0.002 \\
(0.004)\end{array}$ & & $\begin{array}{c}-0.008^{* * *} \\
(0.002)\end{array}$ \\
\hline Positive growth & & $\begin{array}{c}0.000 \\
(0.004)\end{array}$ & & $\begin{array}{c}0.002 \\
(0.002)\end{array}$ & & $\begin{array}{c}0.000 \\
(0.002)\end{array}$ \\
\hline GDP per capita (log) & $\begin{array}{c}0.047 \\
(0.072)\end{array}$ & $\begin{array}{c}0.037 \\
(0.070)\end{array}$ & $\begin{array}{c}0.591^{* * *} \\
(0.182)\end{array}$ & $\begin{array}{c}0.680^{* * *} \\
(0.171)\end{array}$ & $\begin{array}{c}0.073^{* * *} \\
(0.026)\end{array}$ & $\begin{array}{c}0.069 * * * \\
(0.026)\end{array}$ \\
\hline Inflation rate & $\begin{array}{c}0.001 \\
(0.002)\end{array}$ & $\begin{array}{c}0.001 \\
(0.003)\end{array}$ & $\begin{array}{l}-0.002 \\
(0.003)\end{array}$ & $\begin{array}{l}-0.003 \\
(0.003)\end{array}$ & $\begin{array}{c}-0.002^{*} \\
(0.001)\end{array}$ & $\begin{array}{c}-0.002^{*} \\
(0.001)\end{array}$ \\
\hline Unemployment rate & $\begin{array}{c}-0.017^{* * *} \\
(0.003)\end{array}$ & $\begin{array}{c}-0.017^{* * *} \\
(0.002)\end{array}$ & $\begin{array}{c}-0.009^{* *} \\
(0.004)\end{array}$ & $\begin{array}{c}-0.010^{* *} \\
(0.004)\end{array}$ & $\begin{array}{l}0.001^{*} \\
(0.001)\end{array}$ & $\begin{array}{c}0.001^{* *} \\
(0.001)\end{array}$ \\
\hline Economic growth $(-1)$ & $\begin{array}{l}0.006^{*} \\
(0.004)\end{array}$ & & $\begin{array}{c}0.004^{* *} \\
(0.002)\end{array}$ & & $\begin{array}{c}-0.009 * * * \\
(0.001)\end{array}$ & \\
\hline Negative growth $(-1)$ & & $\begin{array}{l}-0.003 \\
(0.011)\end{array}$ & & $\begin{array}{c}-0.006^{*} \\
(0.003)\end{array}$ & & $\begin{array}{c}0.009 * * * \\
(0.002)\end{array}$ \\
\hline Positive growth $(-1)$ & & $\begin{array}{l}0.008^{*} \\
(0.004) \\
\end{array}$ & & $\begin{array}{c}0.008^{* * *} \\
(0.003)\end{array}$ & & $\begin{array}{c}-0.008^{* * *} \\
(0.002)\end{array}$ \\
\hline$N_{\text {macro }}$ & 493 & 493 & 409 & 409 & 1197 & 1197 \\
\hline$N_{\text {micro }}$ & $1,048,008$ & $1,048,008$ & 491,545 & 491,545 & $2,267,428$ & $2,267,428$ \\
\hline$R^{2}$ & 0.062 & 0.063 & 0.051 & 0.051 & 0.095 & 0.095 \\
\hline
\end{tabular}

Clustered standard errors in parentheses

${ }^{*} p<0.1,{ }^{* *} p<0.05,{ }^{* * *} p<0.01$

Dependent variable: life satisfaction (standardised)

Country and year dummies included in models 1-4, state and season dummies in 5-6

Individual controls included: age, gender, education level, employment status, marital status

Economic growth variables are the absolute value of negative and positive growth, 0 otherwise 
The level-of-GDP variable not only captures variation across countries in GDP level, but also the change in GDP compared to the previous year within each country (a country's current GDP $=$ GDP at t- $1+$ GDP growth from $t-1$ to $t$ ). As such, the positive and negative growth terms in the model are redundant, and the estimates for these effects tend to be less precise. $^{7}$

The introduction of one-year lags on growth provides an inconsistent picture across the three data sets. The positive results on lagged growth rates in the Eurobarometer and the Gallup data would appear to indicate that even though positive growth has no immediate impact on life satisfaction (that is, within the year that growth is being measured) it may have a delayed medium-term effect, though the magnitude of this delayed positive effect remains smaller than the immediate impact of negative growth.

\section{Expectations}

The main focus of this paper is whether actual growth rates have an asymmetric relationship to well-being in the present, and Table 7 reports that this finding is robust to the inclusion of individual expectations about the future. As is the case with prospect theory, individuals are forward-looking and anticipate expected gains and losses, the prospect of future gains or losses are reflected in current preferences and subjective well-being and can serve as a reference point (Kőszegi and Rabin, 2006, 2008). The Eurobarometer data include a forwardlooking question that gauges positive and negative growth expectations: "Do you think the economy will get better, worse, or stay the same over the next year?" The same question is also asked in relation to "life in general" rather than the economy. Introducing indicator variables for positive and negative expectations (versus neutral expectations) ${ }^{8}$ allows us to test whether the asymmetric experience of current gains and losses in growth is robust to inclusion of expectations about both life in general as well as the domestic economy. This measure also allows for a preliminary test of whether prospective gains or losses in economic growth are associated with current well-being and, if so, whether there is an asymmetrical relationship.

\footnotetext{
${ }^{7} \mathrm{~A}$ regression model, which allows distinguishing cross-sectional and longitudinal relationships, would include GDP at time t-1 (instead of GDP at time $\mathrm{t}$ ); in this specification, GDP growth from time $\mathrm{t}-1$ to $\mathrm{t}$ is no longer also captured in the GDP term.

${ }^{8}$ Positive (negative) expectations are coded 1 for a response of "better" ("worse"), leaving the "same" response as the omitted category.
} 


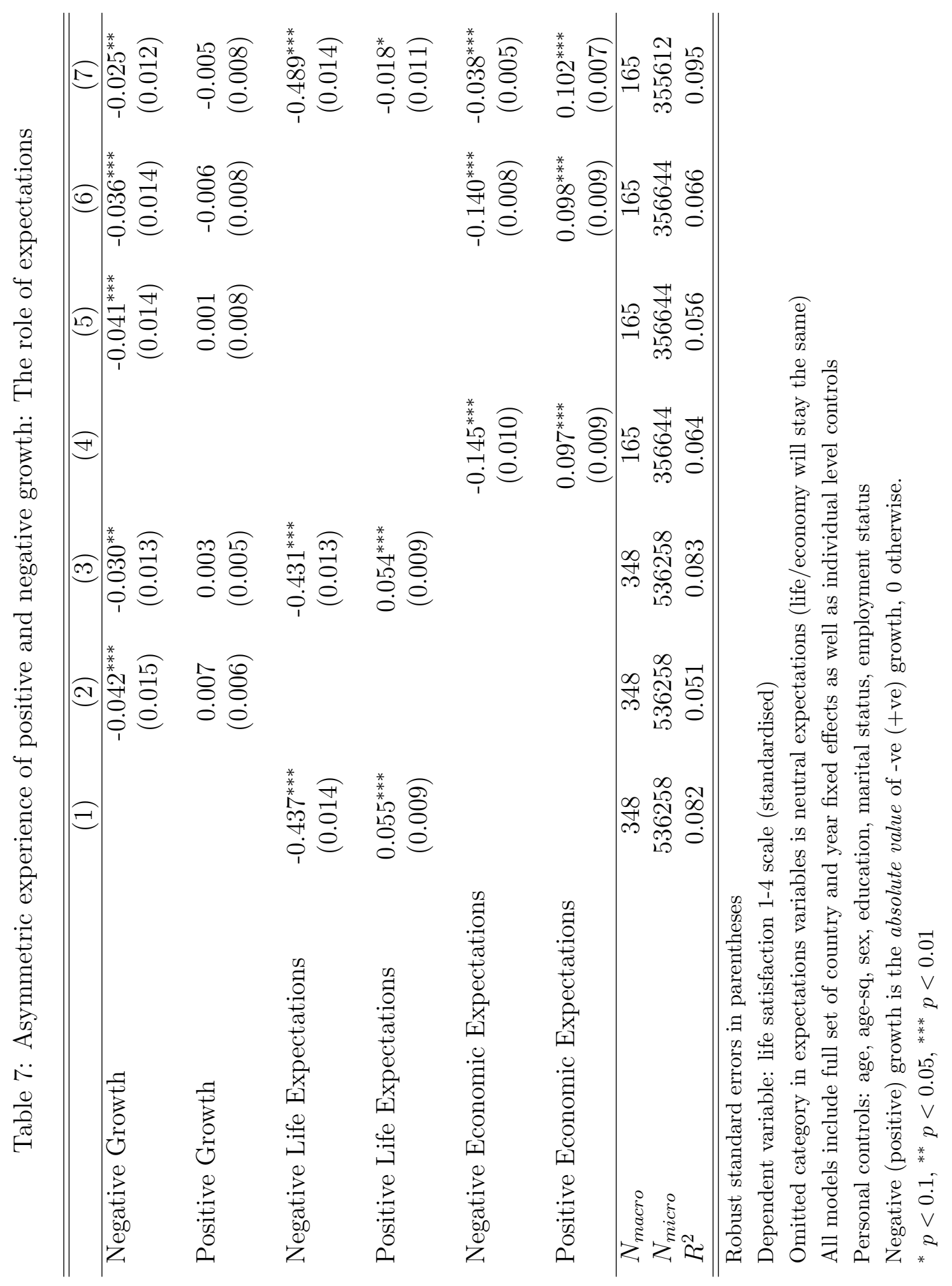


Table 7 (models 1 and 4) reports on simple regressions that indicates that expectationsboth on life and on the economy - are strongly associated with current subjective well-being. In line with the predictions of Prospect Theory in terms of decision utility, we find that negative expectations are associated with a somewhat greater impact on current experienced utility. The prospect of future macroeconomic losses thus appears to loom larger than equivalent macroeconomic gains, and is reflected in individuals' current life satisfaction. At the same time, as reported in Table 7 (models 3, 6, and 7) current negative growth remains significantly associated with current life satisfaction in contrast to current positive growth. These results seem to suggest that there is a simultaneous asymmetry in the experience of actual gains and losses as well as prospective gains and losses.

\section{Discussion}

These findings have a number of theoretical implications. First, the results presented here suggest that loss aversion is not simply a 'hedonic forecasting error' as suggested by Kermer et al. (2006). Our results indicate that individuals actually experience losses more acutely than gains in a macroeconomic setting and this may provide insight into the mechanism that drives the welfare cost of volatile versus smooth business cycles in terms of human well-being. Second, this finding suggests that future research should consider positive and negative economic growth data separately in piecewise analyses in order to correctly interpret the gradient for the general relationship between economic growth and subjective well-being. Third, although we investigate the short-run association of macroeconomic movements and life satisfaction year-to-year (and in the case of the USA, quarter-to-quarter), the finding of macroeconomic loss aversion may be able to provide an alternative explanation for the longterm income-happiness paradox that is complementary to the two most prominent current accounts, namely the psychological mechanisms of hedonic adaptation and social comparison (see Clark et al., 2008).

\section{An alternative explanation for the long-term income-happiness paradox}

The asymmetry in the subjective experience of negative growth may help to reconcile the short versus long-term trends in the income-happiness relationship. When considering the available longer-term data (that cover entire business cycles) it would appear that wellbeing has not risen in most of the world's economically developed nations despite having almost doubled real GDP over the past four decades (Easterlin et al., 2010). The "paradox" resulting from the conflicting findings in the short versus long-term relationship between national income and subjective well-being can perhaps be better understood in light of the results on macroeconomic loss aversion presented here. Periodic recessions can rapidly undo the well-being gains from longer expansionary periods and lead to an insignificant relationship between national income and average well-being when considered in the long 
run.

Imagine a 10-year business cycle consisting of 8 years of steady growth followed by two recession years. If we treat positive and negative growth as qualitatively the same, then we would expect to see a general upward trend (much like that of real national income) -leading to a positive long-run growth-well-being relationship. However, if people are more sensitive to negative growth, than the well-being gains accumulated over 8 years of positive growth can be wiped out by 2 years of negative growth. Over the whole cycle (and over multiple cycles), despite the short-run relationship, the net change in aggregate life satisfaction can be zero. This dynamic can be seen in the theoretical representation of national income and subjective well-being shown on panel (a) of Figure 3. Panel (b) shows the actual relationship using the Eurobarometer data. For each year, the mean of both life satisfaction and real GDP per capita are taken, weighted by national population, for all of the countries sampled by the Eurobarometer in that year. Both measures are shown over time in proportion to their magnitude in 1973. Plots of aggregate time-series of subjective well-being in each of the 15 countries are included in the appendix. Long-run change in societal well-being appears to be a function of how much it has managed to grow in total as well as how volatile growth has been.

This explanation for the long-term income-happiness paradox is complementary to the two most prominent current accounts, namely the psychological mechanisms of hedonic adaptation and social comparison (see Clark et al., 2008). Easterlin (2010, pp. 126-6) also considers the theoretical possibility that aspirations will rise with positive growth in national income but not fall with macroeconomic losses, leading to differential adaptation to gains and losses and the long-run stagnation of aggregate happiness over multiple business cycles.

A better understanding of this dynamic has macroeconomic policy implications and addresses a long-standing debate. On the one hand, a typical reading of the income-happiness paradox suggests that further growth in the developed world is a futile means to the end of improving societal well-being. On the other, researchers who find evidence of a positive relationship between well-being and GDP typically take from this that further economic growth is good for society. Our findings suggest a more nuanced perspective: policy designed to engineer economic "booms", but that risks even relatively short "busts" is unlikely to improve societal well-being in the long-run. Steady positive growth that minimizes the risk of economic contraction seems the most likely route to an improvement in general well-being.

\section{Mechanisms}

Why do individuals experience macroeconomic losses more negatively than they experience equivalent gains positively? While beyond the scope of this paper to provide a conclusive answer, there are several possible avenues to address this important follow-up question. A deep-rooted mechanism could be that individuals simply react more strongly to negative developments. Humans' disproportionate sensitivity to negative stimuli and the general 
Figure 3: Long-term income-happiness paradox and the asymmetric experience of positive and negative growth

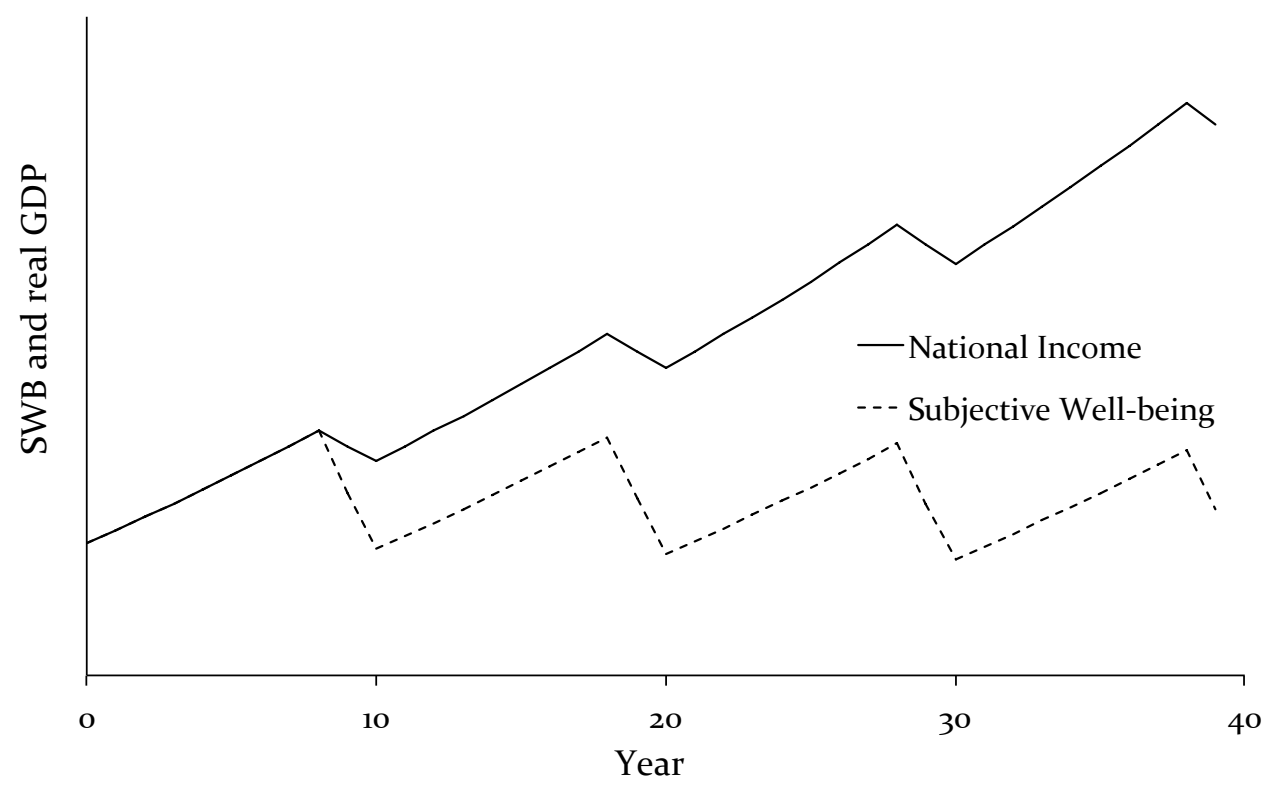

(a) Theoretical representation

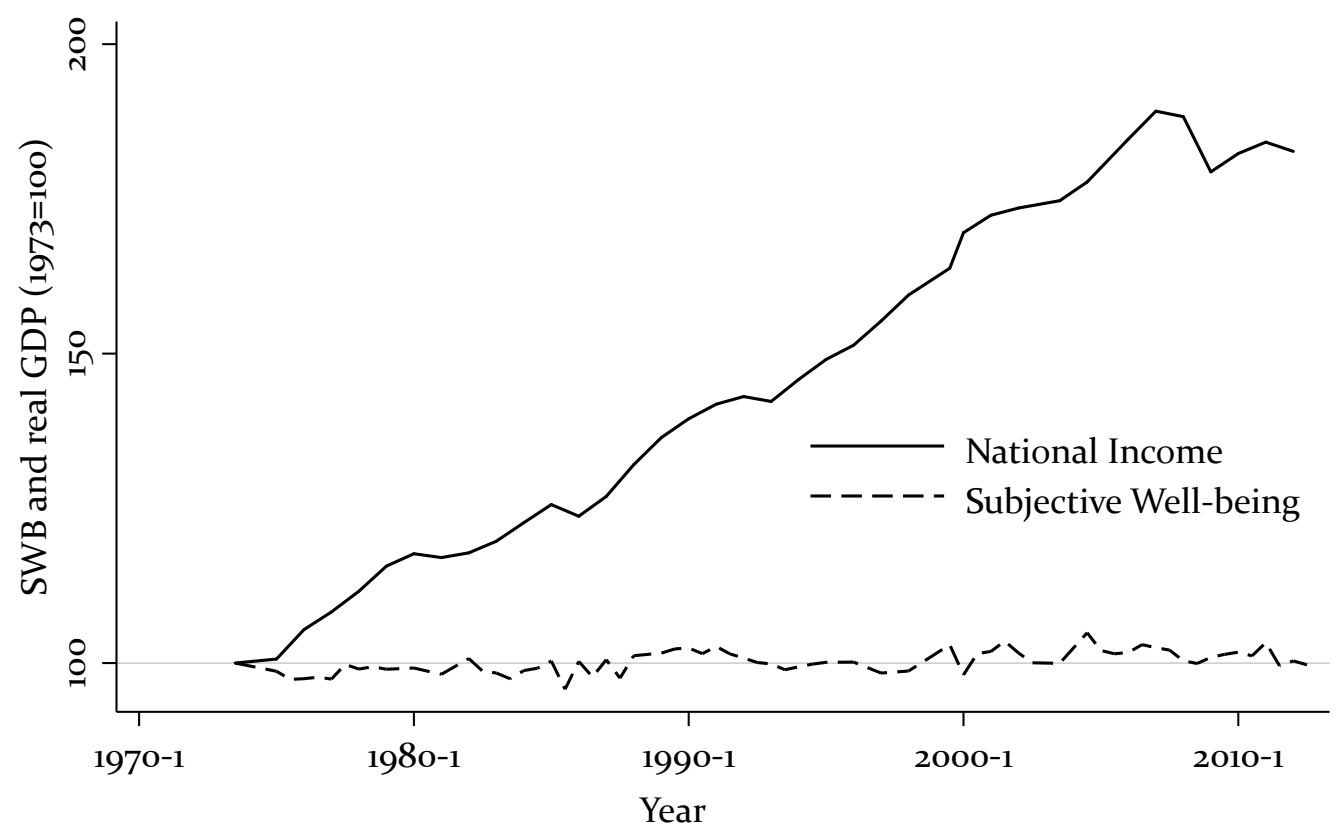

(b) Actual (Eurobarometer EU15 weighted average) 
finding that "bad is stronger than good" (Baumeister et al., 2001) may have an explanation rooted in evolutionary biology (McDermott et al., 2008), since in terms of survival the avoidance of threats is more important than a missed opportunity.

Volatility also leads to uncertainty and such feelings are attention-seeking (Wiggins et al., 1992), and may prevent individuals from adapting to shocks (Wilson and Gilbert, 2008). Periods of economic contraction not only involve a loss of national income but also an increase in economic uncertainty (Bloom, 2009, 2014), which is arguably intensified by the disproportionate coverage of negative news about macroeconomic trends compared to respective positive trends (Soroka, 2006). Luechinger et al. (2010) highlight the role of economic insecurity in increasing angst and stress by showing that the subjective well-being of employed individuals working in the public sector, who in general enjoy more job protection, is less acutely affected by economic shocks than comparable workers in the private sector.

A further, non-psychological conduit between recession and subjective well-being may be consumption behaviour. Rosenblatt-Wisch (2008) shows that negative growth has a disproportionate effect on consumption. Economic uncertainty may lead individuals to consume fewer goods and services compared to any increases brought about by equivalent economic upswings leading to disproportionate losses of well-being.

\section{Limitations}

This study is not without its limitations. First, we note a number of important methodological concerns. On the one hand, there are conceptual differences among the life satisfaction questions used across the three surveys. While the Eurobarometer and BRFSS data include an evaluative question of subjective well-being, the Gallup surveys use Cantril's ladder, responses to which are anchored to the respondent's own reference point of their 'best possible life'. Discrepancies between these two types of questions have been documented (Bjornskov, 2010). Estimates across datasets should therefore be compared with caution. On the other hand, it has been suggested that - similar to responses given to all subjective questionsself-reported subjective well-being is susceptible to mode of interview, with higher levels of evaluative, experienced, and eudemonic measures of well-being reported on telephone compared to face-to-face interviews (Dolan and Kavetsos, 2012). Mode effects have substantial implications for the comparability of our results between surveys given that the Eurobarometer uses face-to-face interviews, the BRFSS phone interviews, and Gallup uses a mix of phone and face-to-face interviews. Moreover, each mode has, in turn, additional implications on reported subjective well-being based on the difficulty of reaching respondents on the phone (Heffetz and Rabin, 2013) and the presence of others during face-to-face interviews (Conti and Pudney, 2011). Our results aim to provide broad evidence in favor of the asymmetric experience of positive and negative growth across multiple sources of data frequently used in the economics literature, rather than highlighting the differences between these. 
Comparing individuals across countries as diverse as those included in the Gallup World Poll is also potentially problematic. Indeed we might well expect the relationship between national income and subjective well-being to be very different in the developed and developing worlds. Reliable macroeconomic data is also difficult to obtain for a number of developing countries included in the Gallup sample.

To simplify the analysis, we have assumed (piecewise) linearity in the income growthwell-being relationship. Further research may relax this linearity assumption in order to test for any diminishing sensitivity to both positive and negative economic growth. It has also been shown, in the developed world at least, that populations adapt to changes in national income (Di Tella et al., 2010); a further avenue of research could well investigate any asymmetries in the way in which individuals adapt to gains and losses in national income. Indeed Easterlin (2010) conjectures that adaptation to losses is likely to be much less complete than adaptation to gains.

An important avenue for further research will focus on more precisely determining the level of economic growth against which populations evaluate gains and losses. In this paper we have assumed the current level of income (that is, zero growth) to be the reference point, negative growth away from the status quo is a loss, positive growth a gain. However, it is conceivable that the reference point might be the previous year's growth rate, or some other growth rate that is considered "normal". A population that experienced $-4 \%$ growth in year $t-1$ may well consider a growth rate of $-1 \%$ in year $t$ a gain, even though it represents an absolute loss of national income. In this sense, individuals get used to a certain level of growth and expect this growth to continue going forward, and then use these expectations as a reference point, judging growth that falls below the expected rate as a loss even if it is actually an absolute gain. Models that include terms for (positive and negative) $\Delta$ growth in order to explain subjective well-being do not uncover any significant relationships, however. An alternative approach is to impose other potential reference points such as $-1 \%$ or $1 \%$ growth. Results from such an approach using non-zero economic growth rates as the spline pivot are reported in the Appendix and present a relatively consistent picture of the asymmetric experience of positive and negative growth when considering different growth rates as reference points.

An important further concern about the finding of macroeconomic loss aversion is that it may well simply reflect the decreasing marginal utility of (national) income. Layard et al. (2008), for example, use subjective well-being data across a number of data sets to find that marginal utility of personal income falls as income rises. To seek to address this, Table A1 reports models that employ negative and positive changes in the natural logarithm of GDP per capita as explanatory variables in the place of growth in untransformed national income. The findings are similar, also identifying a clear asymmetry across the three datasets in the relationship between subjective well-being and economic expansions and contractions. 


\section{Conclusion}

Existing literature has established that subjective well-being covaries with national income to some extent, with the exception of developed nations when considered in long time series. The results presented here build on this earlier research by demonstrating an asymmetry in the subjective experience of positive and negative growth. As a result, they help to reconcile the short versus long-term trends in the income-happiness relationship.

Standard analyses of the income-happiness relationship could arguably be interpreted as 'growth is good.' However, in light of the asymmetric experience of positive and negative growth, an empirically more accurate interpretation of the income-happiness relationship would be that 'recessions are bad'. The problem of labeling results by one pole of a dimension reflects deep linguistic habits rather than the structure of the data (e.g. 'growth' conjures economic expansion whereas almost a quarter of the data in fact cover economic contractions). This semantic problem is widespread in the literature. For example, Kahneman and Deaton (2010) and De Neve and Oswald (2012) consider the relationship between personal income and subjective well-being, finding that earnings and happiness are to some extent predictive of each other. However, in both these papers the underlying data structure is not tested for whether the relationship is perhaps principally accounted for by the negative poles of the earnings and happiness spectrums. This issue also extends beyond the income-happiness relationship. To illustrate, suppose that being very short is more likely to make one miserable than being very tall to make one happy. The relationship would still be described as connecting happiness to 'height'. Piecewise regressions such as detailed in this research can help distill important relationships and aid our interpretation of them.

Academic and policy discussions can overlook whether people are more sensitive to gains or losses in economic growth and focus instead on the benefits of economic growth. As a result, most policies are evaluated by their impact on economic growth as such with less regard to any disproportionate psychological toll that recessions may exert. Our analyses reveal an asymmetry in the way that individuals experience positive and negative macroeconomic fluctuations. We find evidence that self-reported life satisfaction of individuals is more than twice as sensitive to negative growth as compared to positive economic growth rates. Our work indicates the need for nuanced growth policies and the careful use of economic growth data when considering welfare effects in terms of well-being. In sum, we suggest that policymakers and academics should not only evaluate how much the economy has grown but also how the economy has grown. 


\section{References}

Aghion, P., U. Akcigit, A. Deaton, and A. Roulet (2014). Creative destruction and subjective well-being. Mimeo.

Barberis, N. C. (2013). Thirty years of propsect theory in economics: A review and assessment. Journal of Economic Perspectives 27, 173-196.

Barlevy, G. (2004). The cost of business cycles under endogenous growth. American Economic Review 94(4), 964-990.

Barr, B., D. Taylor-Robinson, A. Scott-Samuel, M. McKee, and D. Stuckler (2012). Suicides associated with the 2008-2010 recession in the uk: a time-trend analysis. British Medical Journal 245.

Baumeister, R. F., E. Bratslavsky, C. Finkenauer, and K. D. Vohs (2001). Bad is stronger than good. Review of General Psychology 5(4), 323.

Benjamin, D. J., O. Heffetz, M. S. Kimball, and A. Rees-Jones (2012). What do you think would make you happier? what do you think you would choose? American Economic Review 102(5), 2083-2110.

Benjamin, D. J., O. Heffetz, M. S. Kimball, and A. Rees-Jones (2014). Can marginal rates of substitution be inferred from happiness data? evidence from residency choices. American Economic Review.

Bjornskov, C. (2010). How comparable are the gallup world poll life satisfaction data. Journal of Happiness Studies 11, 41-60.

Blanchflower, D. and A. Oswald (2004). Well-being over time in britain and the usa. Journal of Public Economics 88, 1359-1386.

Bloom, N. (2009). The impact of uncertainty shocks. Econometrica r77(3), 623-685.

Bloom, N. (2014). Fluctuations in uncertainty. The Journal of Economic Perspectives 28(2), $153-175$.

Bowman, D., D. Minehart, and M. Rabin (1999). Loss aversion in a consumption-savings model. Journal of Economic Behavior and Organization 38, 155-178.

Boyce, C. J., A. M. Wood, J. Banks, A. E. Clark, and G. D. Brown (2013). Money, wellbeing, and loss aversion does an income loss have a greater effect on well-being than an equivalent income gain? Psychological Science 24(12), 2557-2562.

Cantril, H. (1965). The pattern of human concerns. New Brunswick, NJ: Rutgers University Press. 
Clark, A. E., E. Diener, and M. A. Shields (2008). Relative income, happiness, and utility: An explanation for the easterlin paradox and other puzzles. Journal of Economic Literature 46(1), 95-114.

Conti, G. and S. Pudney (2011). Survey design and the analysis of satisfaction. Review of Economics and Statistics 93, 1087-1093.

De Neve, J.-E. and A. J. Oswald (2012). Estimating the influence of life satisfaction and positive affect on later income using sibling fixed effects. Proceedings of the National Academy of Sciences 109(49), 19953-19958.

De Santis, M. (2007). Individual consumption risk and the welfare cost of business cycles. American Economic Review 97(4), 1488-1506.

De Vogli, R., M. Marmot, and D. Stuckler (2013). Strong evidence that the economic crisis caused a rise in suicides in europe: the need for social protection. Journal of Epidemiology and Community Health.

Deaton, A. (2008). Income, health, and well-being around the world: Evidence from the gallup world poll. Journal of Economic Perspectives 22(2), 53-72.

Deaton, A. (2012). The financial crisis and the well-being of americans - 2011 oep hicks lecture. Oxford Economic Papers 64(1), 1-26.

Di Tella, R., J. Haisken-De New, and R. MacCulloch (2010). Happiness adaptation to income and to status in an individual panel. Journal of Economic Behavior and Organization $76(3), 834-852$.

Di Tella, R., R. MacCulloch, and A. J. Oswald (2003). The marcoeconomics of happiness. Review of Economic and Statistics 85(4), 809-827.

Dolan, P. and G. Kavetsos (2012). Happy talk: Mode of administration effects on subjective well-being. CEP Discussion Paper, No. 1159, LSE.

Dolan, P. and R. Metcalfe (2012). Measuring subjective wellbeing: Recommendations on measures for use by national governments. Journal of Social Policy 41, 409-427.

Dolan, P., T. Peasgood, and M. White (2008). Do we really know what makes us happy? a review of the economic literature on the factors associated with subjective well-being. Journal of Economic Psychology 29, 94-122.

Easterlin, R. A. (1974). Does economic growth improve the human lot? some empirical evidence. In P. A. David and M. W. Reder (Eds.), Nations and Households in Economic Growth: Essays in Honor of Moses Abramovitz, pp. 89-125. New York: Academic Press.

Easterlin, R. A. (2010). Happiness, growth, and the life cycle. Oxford University Press. 
Easterlin, R. A., L. Angelscu-McVey, M. Switek, O. Sawangfa, and J. S. Zweig (2010). The happiness-income paradox revisited. Proceedings of the National Academy of Sciences 107(52), 22463-68.

Ferrer-i Carbonell, A. and P. Frijters (2004). How important is methodology for the estimates of the determinants of happiness? Economic Journal 114(497), 641-659.

Foellmi, R., R. Rosenblatt-Wisch, and K. Schenk-Hoppe (2011). Consumption paths under prospect utility in an optimal growth model. Journal of Economic Dynamics and Control 35(3), 273-281.

Heffetz, O. and M. Rabin (2013). Conclusions regarding cross-group differences in happiness depend on difficulty of reaching respondents. American Economic Review 103, 3001-3021.

Helliwell, J., R. Layard, and J. Sachs (2013). World Happiness Report. UN Sustainable Development Solutions Network.

Kahneman, D. (1999). Well-Being: The Foundations of Hedonic Psychology, Chapter Objective Happiness. Russell Sage.

Kahneman, D. and A. Deaton (2010). High income improves evaluation of life but not emotional well-being. Proceedings of the National Academy of Sciences of the USA 10\%, 16489-16493.

Kahneman, D., A. B. Krueger, D. A. Schkade, and N. Schwarz (2004). A survey method for characterizing daily life experience: The day reconstruction method. Science 306(5702), 1776-1780.

Kahneman, D. and R. Thaler (2006). Anomalies: Utility maximization and experienced utility. The Journal of Economic Perspectives 20(1), 221-234.

Kahneman, D. and A. Tversky (1979). Prospect theory: An analysis of decisions under risk. Econometrica 47, 263-291.

Kahneman, D., P. Wakker, and R. Sarin (1997). Back to bentham? explorations of experienced utility. Quarterly Journal of Economics 112(2), 375-406.

Kentikelenis, A., M. Karanikolos, I. Papanicolas, S. Basu, M. McKee, and D. Stuckler (2012). The effects of greek economic crisis on health are real. British Medical Journal 345.

Kermer, D. A., E. Driver-Linn, T. D. Wilson, and D. T. Gilbert (2006). Loss aversion is an affective forecasting error. Psychological Science 17(8), 649-653.

Knabe, A., S. Ratzel, R. Schob, and J. Weimann (2010). Dissatisfied with life but having a good day: Time-use and well-being of the unemployed. Economic Journal 120, 867-889. 
Köszegi, B. and M. Rabin (2006). A model of reference-dependent preferences. The Quarterly Journal of Economics, 1133-1165.

Köszegi, B. and M. Rabin (2008). Choices, situations, and happiness. Journal of Public Economics 92(8), 1821-1832.

Krueger, A. B. and D. A. Schkade (2008). The reliability of subjective well-being measures. Journal of Public Economics 92, 1833-1845.

Layard, R. (2005). Happiness: Lessons from a new science. Penguin.

Layard, R., G. Mayraz, and S. Nickell (2008). The marginal utility of income. Journal of Public Economics 92(8), 1846-1857.

Lucas, R. (1987). Models of Business Cycles. New York: Blackwell.

Lucas, R. (2003). Macroeconomic priorities. American Economic Review 93(1), 1-14.

Luechinger, S., S. Meier, and A. Stutzer (2010). Why does unemployment hurt the employed? evidence from the life satisfaction gap between the public and the private sector. Journal of Human Resources 45 (4), 998-1045.

McDermott, R., J. H. Fowler, and O. Smirnov (2008). On the evolutionary origin of prospect theory preferences. The Journal of Politics 70(02), 335-350.

Montagnoli, A. and M. Moro (2014). Everybody hurts: banking crises and individual wellbeing. Sheffield Economic Research Paper Series no. 2014010.

Oswald, A. and S. Wu (2010). Objective confirmation of subjective measures of human wellbeing: Evidence from the usa. Science 327, 576-579.

Oswald, A. J., E. Proto, and D. Sgroi (2009). Happiness and productivity. IZA discussion paper.

Otrok, C. (2001). On measuring the welfare cost of business cycles. Journal of Monetary Economics 47(1), 61-92.

Perez-Truglia, R. (2010). A samuelsonian validation test for happiness data. Working Paper (SSRN 1658747).

Proto, E. and A. Rustichini (2013). A reassessment of the relationship between gdp and life satisfaction. PloS one 8(11).

Rabin, M. (1998). Psychology and economics. Journal of Economic Literature 36(1), 11-46.

Rick, S. (2011). Losses, gains, and brains: Neuroeconomics can help to answer open questions about loss aversion. Journal of Consumer Psychology 21, 453-463. 
Rosenblatt-Wisch, R. (2008). Loss aversion in aggregate macroeconomic time series. European Economic Review 52(7), 1140-1159.

Rutledge, R. B., N. Skandali, P. Dayan, and R. J. Dolan (2014). A computational and neural model of momentary subjective well-being. Proceedings of the National Academy of Sciences www.pnas.org/cgi/doi/10.1073/pnas.1407535111.

Sacks, D., B. Stevenson, and J. Wolfers (2012). The new stylized facts about income and subjective well-being. Emotion 12(6), 1181-1187.

Sacks, D., B. Stevenson, and J. Wolfers (2013). Growth in subjective well-being and income over time. mimeo.

Sacks, D. W., B. Stevenson, and J. Wolfers (2010). Subjective well-being, income, economic development and growth. NBER Working Paper No. 16441.

Sandvik, E., E. Diener, and L. Seidlitz (1993). Subjective well-being: the convergence and stability of self and non self report measures. Journal of Personality 61, 317-342.

Schimmack, U. and S. Oishi (2005). The influence of chronically and temporarily accessible information on life satisfaction judgments. Journal of Personality and Social Psychology 89, 395-406.

Schwarz, N. and F. Strack (1999). Reports of subjective well-being: judgmental processes and their methodological implications. In E. D. D. Kahneman and N. Schwarz (Eds.), Well-Being: The Foundations of Hedonic Psychology, pp. 61-84. New York: Russell Sage.

Senik, C. (2009). Direct evidence on income comparisons and their welfare effects. Journal of Economic Behavior and Organization 72(1), 408-424.

Soroka, S. N. (2006). Good news and bad news: Asymmetric responses to economic information. Journal of Politics 68(2), 372-385.

Stevenson, B. and J. Wolfers (2008). Economic growth and subjective well-being: Reassessing the easterlin paradox. Brookings Papers on Economic Activity 39(1), 1-102.

Strack, F., L. Martin, and N. Schwarz (1988). Priming and communication: The social determinants of information use in judgments of life-satisfaction. European Journal of Social Psychology 18, 429-442.

Stuckler, D., S. Basu, and M. McKee (2011). Effects of the 2008 financial crisis on health: A first look at the european data. The Lancet 387, 124-25.

Sutton, S. and R. J. Davidson (1997). Pre-frontal brain symmetry: A biological substrate of the behavioral approach and inhibition systems. Psychological Science 8(3), 204-10. 
Tversky, A. and D. Kahneman (1991). Loss aversion in riskless choice: A referencedependent model. Quarterly Journal of Economics 106, 1039-1061.

Urry, H. L., J. B. Nitschke, I. Dolski, D. C. Jackson, K. M. Dalton, C. J. Mueller, M. A. Rosenkranz, C. D. Ryff, B. H. Singer, and R. J. Davidson (2004). Making a life worth living: Neural correlates of well-being. Psychological Science 15(6), 367-372.

Vendrik, M. and G. B. Woltjer (2007). Happiness and loss aversion: Is utility concave or convex in relative income? Journal of Public Economics 91(7), 1423-1448.

Wiggins, S., P. Whyte, M. Huggins, S. Adam, J. Theilmann, M. Bloch, S. B. Sheps, M. T. Schechter, and M. R. Hayden (1992). The psychological consequences of predictive testing for huntingtons disease. New England Journal of Medicine 327(20), 1401-1405.

Wilson, T. D. and D. T. Gilbert (2008). Explaining away: A model of affective adaptation. Perspectives on Psychological Science 3(5), 370-386.

Wolfers, J. (2003). Is business cycle volatility costly? evidence from surveys of subjective well-being. International Finance 6(1), 1-31.

Yellen, J. and G. Akerlof (2006). Stabilization policy: A reconsideration. Economic Inquiry 44(1), 1-22. 
Appendix 
Table A1: Asymmetric experience of positive and negative changes in log GPD per capita

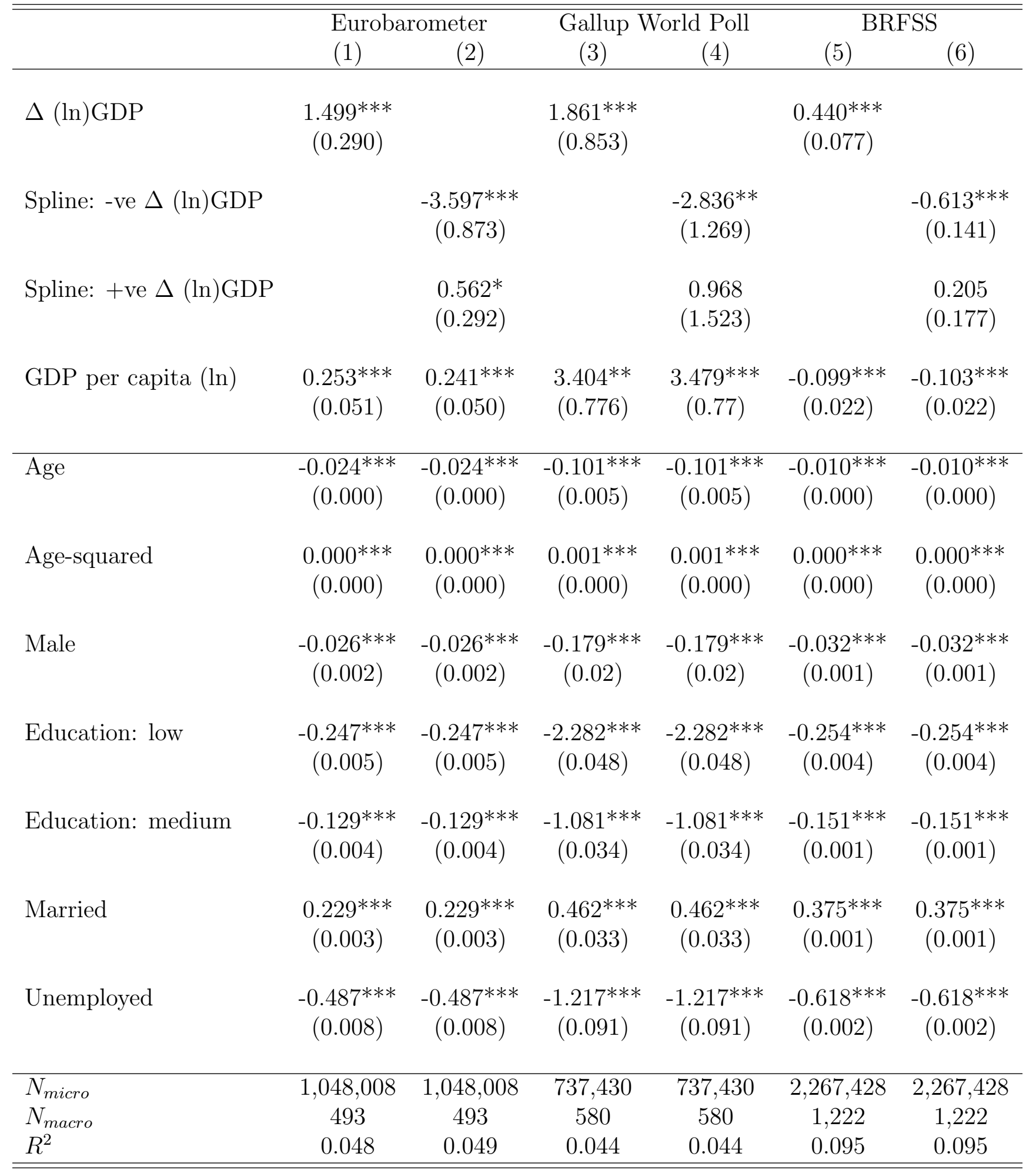

Dependent variable: subjective well-being (standardised)

Country and year dummies included in models 1-4, state and season dummies in 5-6

Clustered standard errors in parentheses

${ }^{*} p<0.1,{ }^{* *} p<0.05,{ }^{* * *} p<0.01$

Splines are the absolute value of negative or positive $\Delta$ GDP, 0 otherwise 
Table A2: Reference Points: Eurobarometer

\begin{tabular}{rrrr}
\hline \hline Reference Point & Neg. Growth & Pos. Growth & Ratio \\
\hline-2 & -0.044 & $0.011^{* * *}$ & 4 \\
-1.5 & $-0.047^{*}$ & $0.010^{* * *}$ & 4.7 \\
-1 & $-0.046^{* *}$ & $0.008^{* *}$ & 5.75 \\
-0.5 & $-0.044^{* *}$ & $0.007^{*}$ & 6.29 \\
-0.1 & $-0.042^{* *}$ & 0.007 & 6 \\
0 & $-0.041^{* *}$ & 0.006 & 6.83 \\
0.1 & $-0.041^{* *}$ & 0.006 & 6.83 \\
0.5 & $-0.038^{* *}$ & 0.006 & 6.33 \\
1 & $-0.035^{* * *}$ & 0.005 & 7 \\
1.5 & $-0.032^{* * *}$ & 0.004 & 8 \\
2 & $-0.028^{* * *}$ & 0.005 & 5.6 \\
\hline \hline
\end{tabular}

${ }^{*} p<0.1,{ }^{* *} p<0.05,{ }^{* * *} p<0.01$

DV: life satisfaction (standardised)

Table A3: Reference Points: Gallup World Poll

\begin{tabular}{rrrr}
\hline \hline Reference Point & Neg. Growth & Pos. Growth & Ratio \\
\hline-2 & $-0.010^{* * *}$ & $0.004^{*}$ & 2.54 \\
-1.5 & $-0.010^{* * *}$ & $0.004^{*}$ & 2.38 \\
-1 & $-0.009^{* * *}$ & $0.004^{*}$ & 2.19 \\
-0.5 & $-0.009^{* * *}$ & $0.004^{*}$ & 2.08 \\
0 & $-0.008^{* * *}$ & $0.004^{*}$ & 2 \\
0.5 & $-0.008^{* * *}$ & $0.004^{*}$ & 1.93 \\
1 & $-0.008^{* * *}$ & $0.004^{*}$ & 2.04 \\
1.5 & $-0.008^{* * *}$ & $0.004^{*}$ & 2.1 \\
2 & $-0.008^{* * *}$ & 0.004 & 2.26 \\
\hline \hline
\end{tabular}

$* p<0.1,{ }^{* *} p<0.05,{ }^{* * *} p<0.01$

DV: Cantril ladder (standardised)

Table A4: Reference Points: Behavioral Risk Factor Surveillance Survey

\begin{tabular}{rrrr}
\hline \hline Reference Point & Neg. Growth & Pos. Growth & Ratio \\
\hline-2 & -0.001 & $0.005^{* * *}$ & 0.21 \\
-1.5 & $-0.006^{* * *}$ & $0.005^{* * *}$ & 1.14 \\
-1 & $-0.008^{* * *}$ & $0.003^{* *}$ & 2.70 \\
-0.5 & $-0.008^{* * *}$ & 0.000 & 9.52 \\
0 & $-0.008^{* * *}$ & 0.001 & 7.08 \\
0.5 & $-0.006^{* * *}$ & $0.004^{* *}$ & 1.60 \\
1 & $-0.005^{* * *}$ & $0.003^{*}$ & 1.81 \\
1.5 & $-0.005^{* * *}$ & 0.004 & 1.31 \\
2 & $-0.005^{* * *}$ & 0.003 & 1.51 \\
\hline \hline
\end{tabular}

${ }^{*} p<0.1,{ }^{* *} p<0.05,{ }^{* * *} p<0.01$

DV: life satisfaction (standardised) 


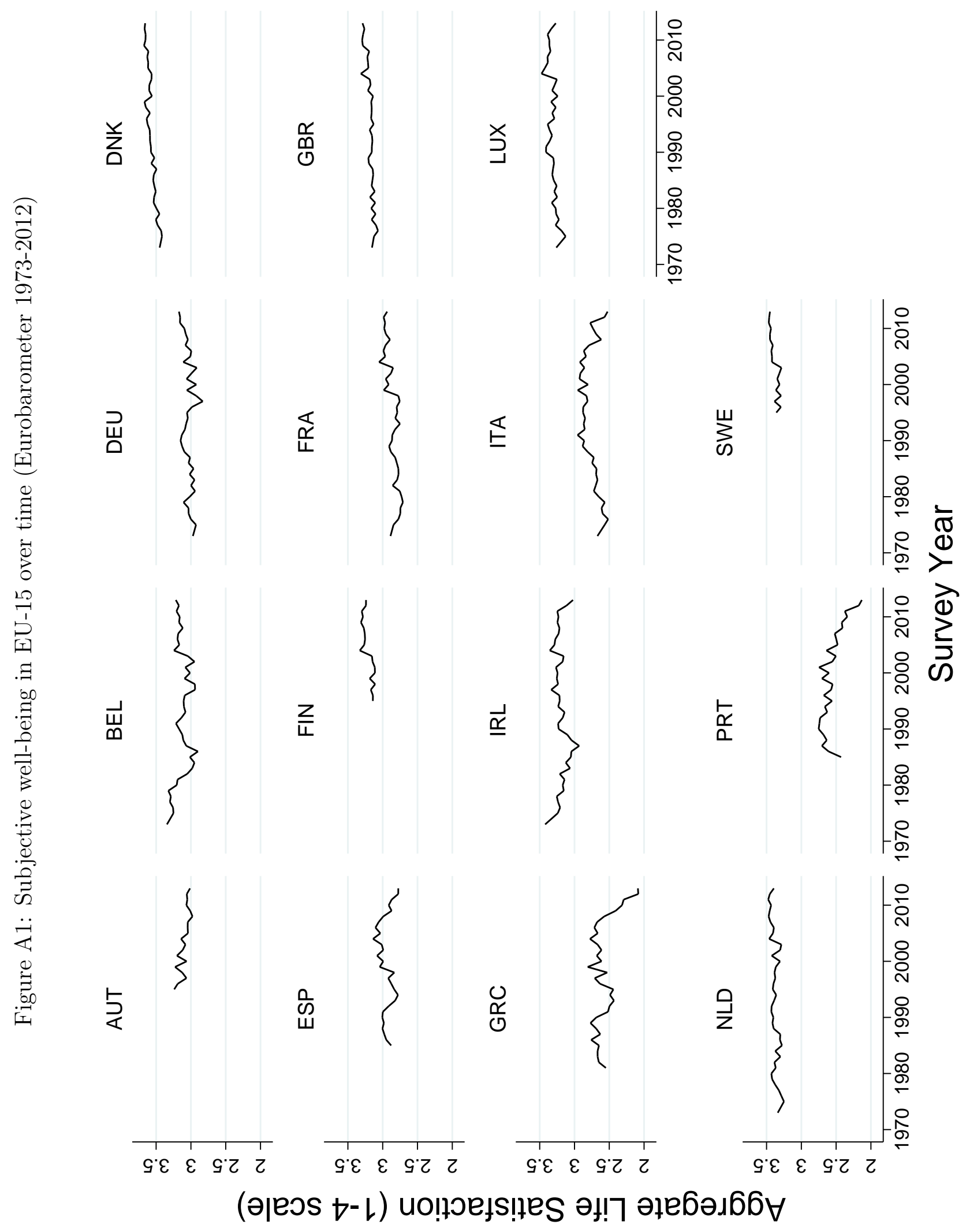

